Indexed by

\title{
WITH REGARD TO THE QUESTION ABOUT THE USE OF ARTIFICIAL BARRIERS IN AREAS WITH MAN-MADE INFLUENCE
}

Scopus

Tatyana Tsurik

Southwest State University,

Kursk, Russian Federation
Anastasia Kolomanich

Southwest State University,

Kursk, Russian Federation
Crossref

$R \partial A D \equiv$

Key words: man-made impact, geochemical barrier, artificial barriers, modernization of structures, chemical reagents, anti-filtration screen

\section{Cite article:}

Tsurik, T., \& Kolomanich, A.[2021]. With regard to the question about the use of artificial barriers in areas with man-made influence. Journal of Applied Engineering Science, 19(2), 522 -

525.DOI:10.5937/jaes0-31626

Online aceess of full paper is available at: www.engineeringscience.rs/browse-issues 


\title{
WITH REGARD TO THE QUESTION ABOUT THE USE OF ARTIFICIAL BARRIERS IN AREAS WITH MAN-MADE INFLUENCE
}

\author{
Tatyana Tsurik*, Anastasia Kolomanich \\ Southwest State University, Kursk, Russian Federation
}

One of the ways to improve the environmental situation in various regions of the world has become the improvement of technologies for protection against hazardous pollution in soil, atmosphere, groundwater. The article is devoted to the analysis of the conceptual proposal within the framework of participation in the competition "Students reinventing cities. The promising methods of elimination and localization of environmental pollution using geochemical barriers are outlined. Examples of natural and artificial geochemical barriers are considered. Attention is drawn to the possibility of using anti-filtration screens as artificial barriers in areas with passive technogenic impact. The potential of using artificial barriers for the safe cultivation of plant crops at the former Payatas controlled waste disposal facility in Quezon City, Philippines is being identified. The importance of creating green spaces in the territory with limited opportunities for economic use is justified.

Key words: man-made impact, geochemical barrier, artificial barriers, modernization of structures, chemical reagents, anti-filtration screen

\section{INTRODUCTION}

In the structure of the quality of life, the environmental component still plays a key role [1, 2, 3]. This problem is particularly acute for residents of those regions of the world where poverty and social tensions make it difficult to implement environmental programs. Contamination of soils and water bodies as a result of human production activities is one of the most important environmental problems in our time. The lithosphere (the upper shell of the Earth) and the hydrosphere have been actively used by humans for hundreds of years in mining and agriculture [4]. Progress in the field of production, intensive use of natural resources, the introduction of scientific and technological advances are accompanied by the emergence and increase in the level of negative factors of anthropogenic impact on the environment.

Due to the constant anthropogenic impact on the ecological systems of the environment and the introduction into biochemical cycles, negative changes in the ecological and geochemical indicators of the environment occur [5]. The most significant type of environmental pollution is considered to be chemical pollution. One of the most important factors of chemical pollution of soils, natural landscapes, ground and ground waters is the content of toxic heavy metals $(\mathrm{HM})$ in them, such as chromium ( $\mathrm{Cr}$ ), cobalt (Co), cadmium ( $\mathrm{Cd})$, lead $(\mathrm{Pb})$, etc.

An equally important problem is the subsequent use of contaminated areas. A rapidly growing population and limited arable land make it relevant to research contaminated land for food production. At the same time, crop production in contaminated areas has a number of obstacles due to risks to human health and the lack of developed innovative farming practices [6]. The safety and sustainability of crop cultivation involves the development of strategies for the productive use of contaminated land [7].

\section{THEORY AND EXPERIMENTAL}

The main direction of improving the environmental situation is the improvement of technological schemes of enterprises: modernization of waste and emission treatment systems, waste recycling, etc. [4] Modern environmental protection structures for wastewater treatment, air emissions and isolation of storage areas for solid and liquid toxic waste, as a rule, require large capital costs, significant energy and material resources during their operation. In this connection, the problem arises of minimizing the man-made impact of industry on the environment in cost-effective ways.

One of the promising methods for the elimination and localization of soil and water pollution is the creation of man-made geochemical barriers that can prevent the spread of pollution. In recent decades, to protect the environment from pollution, there has been a tendency to use geochemical barriers, which in some cases make it possible to abandon the construction of complex treatment facilities and other expensive environmental protection measures. In 1961 Perelman A.I. proposed to use the term "geochemical barriers" to name such areas of the hypergenetic zone, in which a sharp change in migration conditions occurs at a short distance, which leads to the concentration of chemical elements [4].

According to modern concepts, a geochemical barrier is an open, nonequilibrium, dynamic, self-organizing system with many factors that cause the precipitation of elements $[5,8,9]$. 
Nature is arranged in such a way that it protects itself from aggressive and passive environmental influences and anthropogenic activities; the simplest and most common example of a natural geochemical barrier is a forest belt. On the surface of the leaves of trees, dust settles, arising from the vital activity of nature and man, which significantly pollutes the biosphere (the totality of the lithosphere, hydrosphere and troposphere), despite the fact that the vegetation of the forest belt itself may not be affected by harmful settling substances. Soils, clayey soils and waters, which retain various types of chemical pollutants, are also considered a simple example of a natural geochemical barrier.

\section{EXPERIMENTAL SECTION}

To solve various problems, such as environmental protection, mineral processing, engineering protection of the territory, etc., natural geochemical barriers can be used. The area of application of geochemical barriers was originally extended to solve a number of problems in the oil and mining industry [11]. As a result of the termination of the operation of coal basins due to the uncontrolled discharge of contaminated groundwater, the state of the environment is significantly deteriorating [12]. Technological solutions to eliminate this problem require large material costs, and scientists are exploring the scientific basis for creating geochemical barriers that demonstrate low cost and relative ease of use. At present, the accumulation of pollutants in the soil is continuously increasing, therefore, the field of using geochemical barriers is expanding. In addition, industrial waste can be used as natural geochemical barriers. Their repeated use as natural geochemical barriers to weaken the migration of heavy metals has a high potential for protecting soil and groundwater and is becoming a promising research area and method for protecting the ecosystem [13, 14, 15]. To protect the environment, it is possible to use specially created barriers, which are called artificial barriers. Special technologies are being developed to create artificial geochemical barriers for various purposes, for example, to improve water quality $[16,17]$.

Special technologies are being developed to create artificial geochemical barriers. Depending on the specifics and economic feasibility, various materials and substances are used to create barrier structures (Fig. 1).

\section{RESULTS AND DISCUSSION}

We believe that to create artificial barriers, it is advisable to use a combination of materials - building structures with the use of chemical reagents on separate parts of the structure, along with natural materials. The combination of two types of materials can significantly reduce active and passive anthropogenic impact on the environment, for example, soil pollution during production activities. These situations may occur on the territory of existing and former industrial enterprises.

Consider as an example the site of the former Payatas controlled waste disposal facility in Quezon City, Philippines (Figure 2). The closure of the burial ground between 2010 and 2017 provides an opportunity to use this site in an innovative and environmentally friendly way, which opens up economic prospects for the development of the local community. Currently, a competition has been announced for the development of a concept for the reconstruction and restoration of this area, aimed at finding measures to reduce greenhouse gas emissions, increase resilience to climate change and restore ecosystems and biodiversity [18]. The main condition is to create the possibility of safe cultivation of crops.

To reduce the impact of contaminated soils, toxic vapors and gases on crops, various types of barriers with anti-filtration and anti-migration properties are used [4]. These barriers are anti-filtration screens. As a material of screens can be used: concrete, reinforced concrete, polymer compounds in the composition of concrete, synthetic materials.

Anti-seepage screens are made of sheet or roll polymeric film membranes, laid directly on the prepared base without protective coatings [8], (Fig. 3, mark 5). The screen canvases can be fastened using an anchorage, which is installed on the slope ledge, sprinkled with soil or fixed with reinforced concrete structures (Fig. 3, mark 2).

The method of environmental protection using screens with zero or minimum permeability is more often used when installing landfills, this barrier prevents the spread of hazardous chemicals from the structure into the layers of the biosphere. However, the impermeable material allows the possibility of its use for the protection and safe production of agricultural products from individual chemical elements within man-made halos. So, on the territory

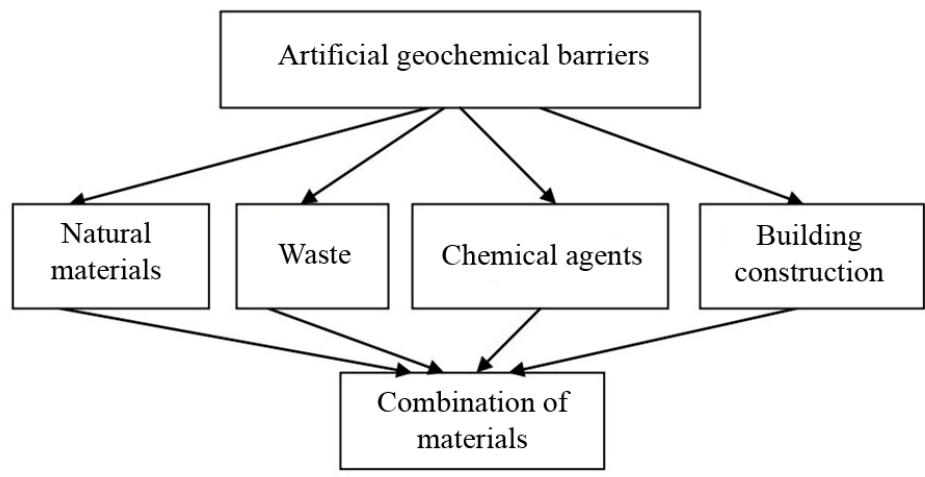

Figure 1: Scheme "Materials for the creation of artificial geochemical barriers" 


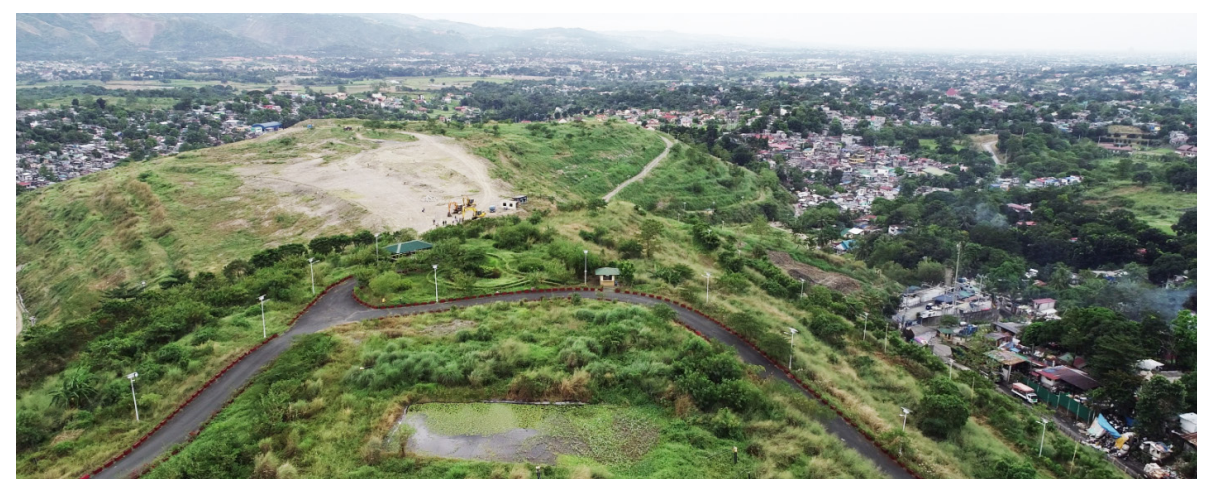

Figure 2: Payatas Controlled Disposal Facility, Quezon City, Philippines

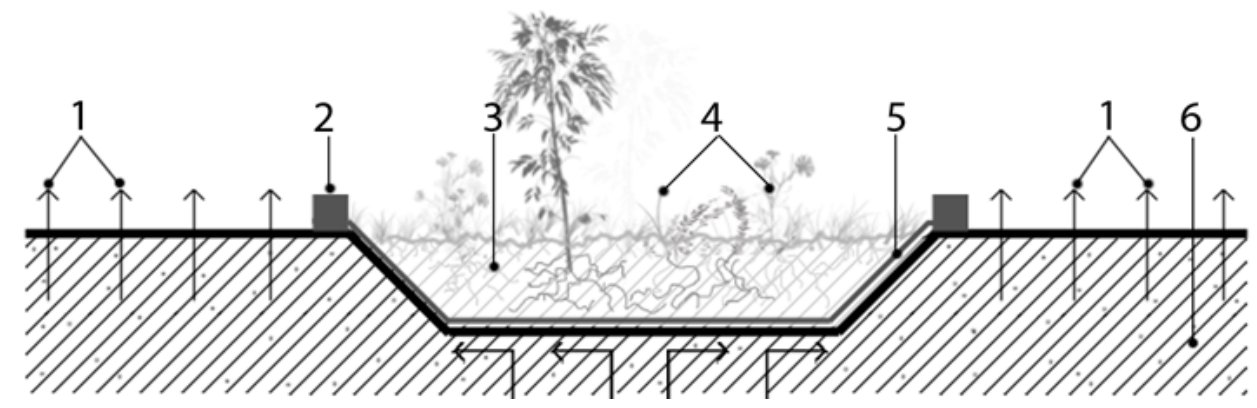

Figure 3: Scheme of application of an anti-filtration screen on the territory of a former industrial enterprise: 1 - release of contaminated substances; 2 - anti-filtration artificial barrier; 3 - cleaned soil; 4 - grown crops; 5 - the canvas of the anti-filtration screen; 6 - contaminated soil

of the Payatas enterprise, it is possible to resolve the issue of the safe location of areas for the cultivation of crops. Figure 3 shows a diagram of the use of an anti-seepage screen on the territory of a former industrial enterprise.

\section{CONCLUSIONS}

The basis for the implementation of programs to improve the efficiency of environmental protection from pollution and to obtain economic benefits from the territory should be a set of measures, which includes both methods of arresting substances hazardous to human life and methods of transforming potentially hazardous territories into green open spaces. Devices with impervious screens can be used in areas with technogenic geochemical anomalies for local protection of territories from pollution resulting from the release of hazardous substances. The proposed solution to the problem of improving the environmental situation with the use of impervious screens will protect the vegetation of the territory of the former Payatas controlled waste disposal facility in Quezon City. This, in turn, can help optimize the state of the production site for its further use and improve the living standards of the region's population.

\section{REFERENCES}

1. Polyakova, T., Tsurik T. (2019). Urban environment quality and its impact on socioeconomic development. Economic Annals - XXI, vol.180, no. 11-12, 155-164, DOI: https://doi.org/10.21003/ea.V180-17.
2. Pozdnyakov, A. (2017). Basic methodological principles for solving environmental problems in urban planning. ARPN Journal of Applied Engineering Science, vol. 15, no. 3, 300-306, DOI: 10.5937/jaes1514665.

3. Pozdnyakov A., Tsurik T. (2020). The concept of a system of comfortable public spaces in the city of Kursk. Environmental Risks and Safety in Mechanical Engineering (ERSME-2020), p. 2-9.

4. Blinov S. (2000). Fundamentals of the use of geochemical barriers for environmental protection. Perm: Autoref. diss. for the degree of Candidate of Geological and mineralogical sciences.

5. Maksimovich N. G., Khairulina E. A. (2016). Geochemical barriers and ensuring environmental safety in areas with intensive technogenic impact. Theory and methods of research in the natural sciences. $p$. 228-240.

6. Abhilash P. C., Tripathi V., Edrisi S. A., Dubey R. K., Bakshi M., Dubey P. K., Singh H. B., Ebbs S. D. (2016). Sustainability of crop production from polluted lands. Energy, Ecology and Environment, vol. 1, 54-65, DOI: https://doi.org/10.1007/s40974-0160007-x.

7. Jacobsen S.E., Sørensen M., Pedersen S.M., Weiner J. (2013) Feeding the world: genetically modified crops versus agricultural biodiversity. Agronomy for Sustainable Development, vol. 33, no. 4, 651-662, DOI:10.1007/s13593-013-0138-9. 
8. Maximovich N. (2010). Theoretical and applied aspects of use geochemical barriers to environmental protection. Engineering geology. no. 9, p. 20-28.

9. Khaustov A, Redina M. (2019). Geochemical barriers as structural components of the geochemical systems evolution. 16th International Symposium on Water-Rock Interaction (WRI-16) and 13th International Symposium on Applied Isotope Geochemistry (1st IAGC International Conference), p. 1-5.

10. Maximovich N., Khayrulina E. (2016). Artificial geochemical barriers for environmental improvement in a coal basin region. Environmental Earth Sciences. vol. 72, 1915-1924. DOI:10.1007/s12665-0143099-7.

11. Ostakh, O., Ostakh, S., Kusheeva, V., Grechishcheva, N., Zavorotny, V. (2020). Geochemical barriers for the arrangement of the oil and gas fields infrastructure and the protection of the adjacent territories. International Multidisciplinary Scientific GeoConference Surveying Geology and Mining Ecology Management, SGEM, 2020-August (5.1), p. 387392.

12. Okamoto M, Kobayashi T, Sakamoto M (2006). Physical properties of sediments deposited in the minewater from a closed coal mine. Engineering geology for tomorrow's cities. 10th Congress of the International Association for Engineering geology and the Environment, Nottingham, United 2006, Electronic optical disks (CD-ROM).

13. Twardowska J. et al. (2006). Using abundant waste and natural materials for soil and groundwater protection against contamination with heavy metals. Prospects and Areas of Application. Soil and Water Pollution Monitoring, Protection and Remediation. p. 231-247.
14. Maximovich, N.G., Osovetskiy, B.M., Blinov, S.M. Geochemical barriers and environment protection (2018). ISRM International Symposium 2000.

15. Antoninova, N.Yu., Sobenin, A.V., Shubina, L.A.Assessment of usability of industrial waste in construction of geochemical barriers (2020) Mining Informational and Analytical Bulletin, 2020 (12), p. 78-88.

16. Abd Rashid, N.A., Roslan, M.H., Rahim, N.A., Abustan, I., Adlan, M.N. (2015). Artificial barrier for riverbank filtration as improvement of soil permeability and water quality. Jurnal Teknologi, val. 74, no.11, p. 51-58, DOI: https://doi.org/10.11113/jt.v74.4860.

17. Chanturiya, V., Masloboev, V., Makarov, D., Mazukhina, S., Nesterov, D., Men'Shikov, Y. (2011). Artificial geochemical barriers for additional recovery of non-ferrous metals and reduction of ecological hazard from the mining industry waste. Journal of Environmental Science and Health - Part A Toxic/Hazardous Substances and Environmental Engineering, val. 46, no.13, p. 1579-1587, DOI: 10.1080/10934529.2011.609435.

18. Payatas Controlled Disposal Facility, Quezon City, Philippines / A global competition for students to share their vision for green \& thriving city neighborhoods, from https://www.c40reinventingcities. org/en/students/sites-in-competition/payatas-controlled-disposal-facility-1477.html, accessed on 2021-23-03. 